\title{
Role of Hysterolaparoscopy in Infertility
}

\author{
Virupakshi Ajjammanavar ${ }^{1}$, Nayana D Hiremath ${ }^{2}$, Jayashree $\mathrm{S}^{3}$
}

\begin{abstract}
Introduction: Hysterolaparoscopy often brings to light the hitherto unexpected pathology. The objective of this study was to evaluate various etiological factors in infertility by hysterolaparoscopy and to evaluate therapeutic interventions done during hysterolaparoscopy.

Materials and methods: Women posted for hysterolaparoscopy for infertility workup in JSS hospital during the period from November 01, 2014, to October 31, 2016, were included in the study. First hysteroscopy was performed. In hysteroscopy, endocervical canal was visualized for any growth or polyps. Diagnostic laparoscopy was performed using a 30-degree deflection angle telescope powered with a fiber-optic cable for light source.

Results: On hysteroscopy, out of 90 cases, 68 (75.6\%) had normal findings, 10 (11.1\%) had endometrial polyps, 5 (5.6\%) had septate uterus, 3 (3.3\%) had hyperplastic endometrium, and there was 1 case each of submucous fibroid, atrophic endometrium, intrauterine adhesions, and hypoplastic uterus. Laparoscopic interventions were performed in the form of ovarian cystectomy in 17 (18.8\%), paraovarian cystectomy in $3(3.3 \%)$, adhesiolysis in $2(2.2 \%)$ cases, drilling of polycystic ovaries in $26(28.8 \%)$ cases, fulguration or excision of endometriosis nodules in 4 (4.4\%), myomectomy in $7(7.7 \%)$ cases), fimbrial cystectomy in $2(2.22 \%)$, and unilateral salpingectomy done in $2(2.22 \%)$.

Conclusion: Hysterolaparoscopy is an effective and safe tool in comprehensive evaluation of infertility to diagnose and treat the various pathological conditions in a single sitting.

Keywords: Hysterolaparoscopy, Infertility, Pathological conditions, Uterus.

International Journal of Infertility and Fetal Medicine (2020): 10.5005/jp-journals-10016-1196
\end{abstract}

\section{INTRODUCTION}

Infertility affects about $10-15 \%$ of reproductive-age couples. Although the prevalence of infertility is believed to have remained relatively stable during past 40 years, the demand for evaluation and infertility treatment has increased. ${ }^{1,2}$

Majority of pelvic pathology is frequently not well appreciated by routine pelvic examinations and the usual diagnostic procedures. Hysterolaparoscopy becomes the "third eye" of the gynecologist in diagnosis of infertility. Laparoscopy and hysteroscopy can be used for both diagnostic and operative purposes.

Laparoscopy is considered the gold standard for diagnosing tubal and peritoneal disease. It has got an advantage of direct visualization of the pelvic organs and the peritubal status, which provides greater information when compared to hysterosalpingography and ultrasonography.

Hysteroscopy has become the gold standard for diagnosis of intrauterine abnormalities. Small intrauterine lesions such as adhesions, polyps, or submucous myomas are diagnosed much more precisely by hysteroscopy.

The question of tubal morphology and patency, ovarian morphology, an unsuspected pelvic pathology, and uterine cavity abnormalities can all be resolved with accuracy at one session. Additionally, therapeutic procedures can also be done in the same sitting.

Hence, hysterolaparoscopy is an effective and safe tool in comprehensive evaluation of infertility to diagnose and treat the lesions of pelvis in the same time. ${ }^{2}$

\section{Materials and Methods}

This cross-sectional study was done for a period of 2 years in Department of Obstetrics and Gynecology, JSS Medical College, Mysuru, from October 2014 to August 2016.
${ }^{1,3}$ Department of Obstetrics and Gynaecology, JSS Medical College, JSSAHER, Mysuru, Karnataka, India

${ }^{2}$ Department of Obstetrics and Gynaecology, RajaRajeshwari Medical College and Hospital, Bengaluru, Karnataka, India

Corresponding Author: Jayashree S, Department of Obstetrics and Gynaecology, JSS Medical College, JSSAHER, Mysuru, Karnataka, India, Phone: +91 9620255534, e-mail: drjayashrees@gmail.com

How to cite this article: Ajjammanavar V, Hiremath ND, Jayashree S. Role of Hysterolaparoscopy in Infertility. Int J Infertil Fetal Med 2020;11(1):5-10.

Source of support: Nil

Conflict of interest: None

\section{Inclusion Criteria}

Women with primary or secondary infertility admitted in JSS hospital for hysterolaparoscopy.

\section{Exclusion Criteria}

- Active pelvic infections

- Medical disorders which are contraindication for anesthesia

Prior to commencement of the study, ethical clearance was obtained from Human Ethics Committee. A total of 90 women aged between 18 years and 40 years with primary or secondary infertility willing for the infertility workup were included in study. A detailed medical history was taken in all cases. This was followed by a detailed medical examination and relevant examination of the husband. Patients satisfying the selection criteria were informed in detail about the nature of study, and a written informed consent was obtained prior to procedure. After admission, demographic data such as age, religion, education, and socioeconomic status 
were obtained. A detailed history and clinical examination was done. The scheduled investigations were done to determine fitness for surgery. Patient was admitted one day prior to the procedure, and preanesthetic checkup was done. Hysterolaparoscopy was scheduled in preovulatory period between day 5 and day 10 of cycle for infertility evaluation after informed consent (Figs 1 and 2).

Hysterolaparoscopy was done under general anesthesia. First hysteroscopy was performed. In hysteroscopy, endocervical canal was visualized for any growth or polyps. Uterine cavity was examined for the presence of septum, any congenital malformation, fibrotic bands, polyps, myomas, endometrial appearance, thickness, and color. Both the tubal ostia were visualized.

Diagnostic laparoscopy was performed using a 30-degree deflection angle telescope powered with a fiber-optic cable for light source. Panoramic view of the abdomen was obtained. Stepwise evaluation was made in the following manner:

\section{General}

To start with a general assessment of peritoneal cavity, especially the lower part of abdomen and pelvis was made to note any obvious pathology in the form of adhesions, endometriosis, or any gross deviations from the normal appearance.

Uterus, tubes and ovaries: The size and shape of the uterus was recorded. Any apparent congenital malformations such as arcuate uterus, bicornuate uterus, or rudimentary uterine horn were looked for and recorded. If any adhesions existed between the uterus, adnexae, omentum etc., they were recorded. Tubes were identified by tracing them from cornual end to fimbrial end. Apparent tortuosity of the tubes, any pathology affecting or involving the tubes was looked for and recorded. In cases where anatomy was distorted, round ligament was visualized first and tubes were traced. With respect to ovaries, size, shape, surface, color, presence of cysts and relation with tubes was noted.

Pelvic peritoneum including pouch of Douglas: Any pathology in the form of endometriosis, pelvic inflammation, and presence of fluid was recorded when seen.

Laparoscopic chromopertubation was performed for testing tubal patency in which methylene blue dye was injected with a 20-ml syringe via Leech Wilkinson cannula intracervically, and spillage of dye from the fimbrial end of tube was visualized.

Surgical interventions were carried out whenever required during the procedure which included hysteroscopy interventions, such as intrauterine adhesiolysis, hysteroscopic polypectomy, hysteroscopy septal resection, endometrial curettage, tubal cannulation, hysteroscopic sub mucosal fibroid resection, etc., and laparoscopic interventions, such as ovarian drilling, ovarian cyst excision, fulguration of endometriotic lesions, laparoscopic myomectomy, etc. Patients were kept for a period of 24 hours in the hospital postoperatively.

\section{Results}

Out of 90 subjects, 66 (73.3\%) had primary infertility and 24 (26.7\%) had secondary infertility. The age distribution of these two groups is shown in Table 1.

Out of 90 cases studied, 68 (75.6\%) had normal findings, 10 (11.1\%) had endometrial polyps, 1 (1.1\%) had submucous fibroid, 5 (5.6\%) had septate uterus, 3 (3.3\%) had hyperplastic endometrium, and 1 each had atrophic endometrium, intrauterine adhesions, and hypoplastic uterus, respectively (Table 2 ).

Laparoscopic findings of uterus in 90 cases for infertility findings were as follows: 74 (78.\%) of them had normal findings, 12 (13.3\%) of them had fibroid uterus, and 1 (1.1\%) each had unicornuate uterus and hypoplastic uterus (Table 3 ).

Laparoscopic findings of pelvic pathology showed endometriosis in 27 cases of which minimal endometriosis was seen in 10 (32.3\%), mild in 6 (19.4\%), moderate in 9 (29\%), and severe in $2(6.5 \%)$ cases. Four (12.9\%) of them had omental adhesions (Table 4).

Seventy-four (60\%) of them had normal fallopian tubes. Pathological findings included peritubal adhesions, hydrosalphinx, tortuousity, stretching and kinking of tubes, tubo-ovarian mass, hematosalphinx, and absent tubes. One of the tubes could not be visualized due to adhesions in 4 cases (Table 5).

Laparoscopic findings of ovaries are depicted in Table 6. Polycystic ovaries were seen in $30 \%$ of cases, and endometriotic cyst was noted in 11 cases. Ovaries could not be visualized due to adhesions in four cases.

Chromopertubation findings of 90 cases showed bilateral spillage in 67 (74.4\%) patients. Unilateral spillage was seen in 15 (16.7\%), and there was tubal block in 8 (8.9\%) cases (Table 7).

Laparoscopic interventions were performed in the form of ovarian cystectomy in $17(18.8 \%)$, paraovarian cystectomy in $3(3.3 \%)$, adhesiolysis in 2 (2.2\%) cases, drilling of polycystic ovaries in $26(28.8 \%)$ cases, fulguration or excision of endometriosis nodules in 4 (4.4\%), myomectomy in 7 (7.7\%) cases), fimbrial cystectomy in $2(2.22 \%)$, and unilateral salpingectomy done in $2(2.22 \%)$ (Table 8$)$.
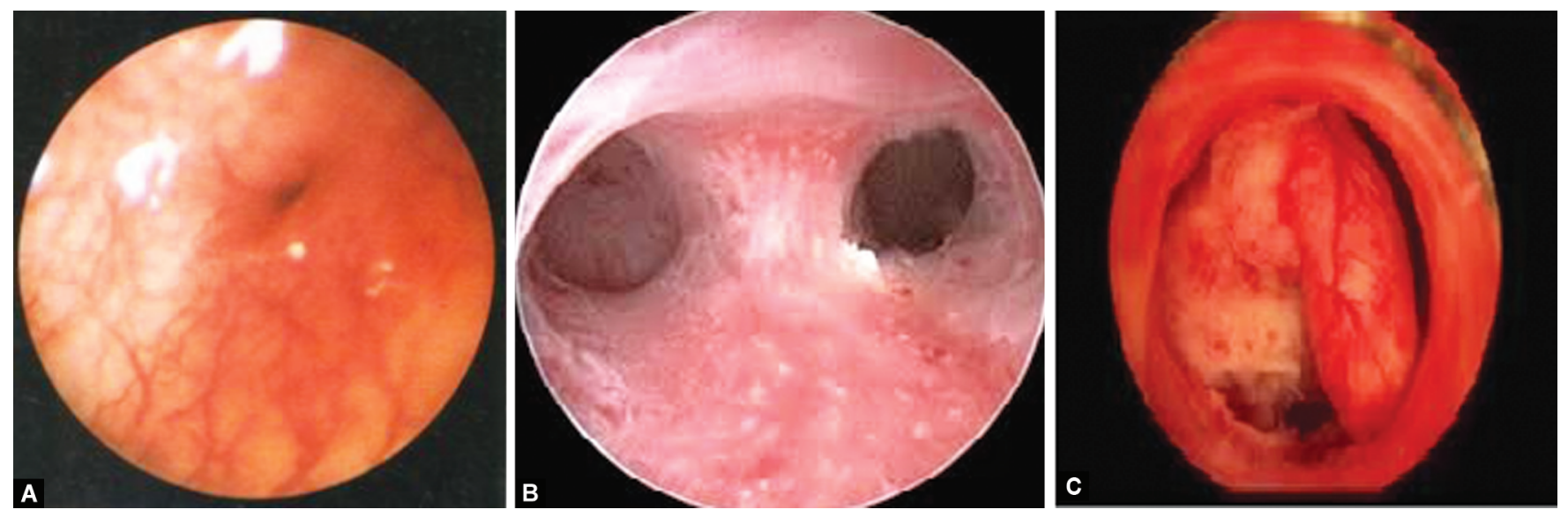

Figs 1 A to C: Hysteroscopy images 

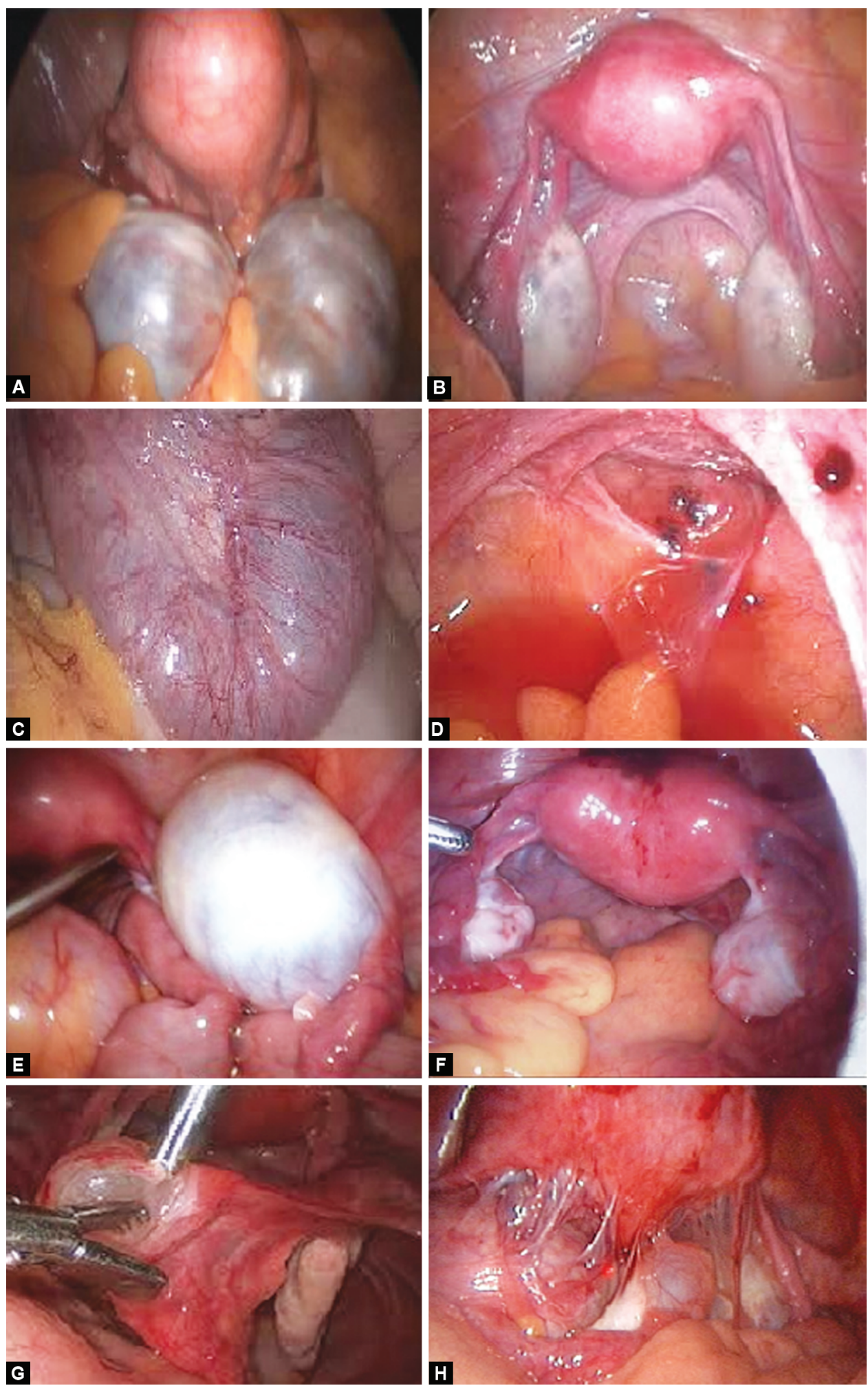

Figs $2 \mathrm{~A}$ to $\mathrm{H}$ : Laparoscopy images

Hysteroscopic interventions were performed in the form of curettage in 08 (33.3\%), hysterocopic cannulation in 2 (8.3\%), polypectomy and septal resection in $5(20.8 \%)$ cases each, submucosal fibroid resection in 1 (4.2\%) case, and tubal block released in 2 (8.3\%) (Table 9).

\section{Discussion}

The present study was a cross-sectional study done for period of 2 years in Department of Obstetrics and Gynecology, JSS Medical College, Mysuru, from October 2014 to August 2016. In our study, 
Table 1: Distribution according to age and type of infertility in the study subjects

\begin{tabular}{llll}
\hline $\begin{array}{l}\text { Age group (in } \\
\text { years) }\end{array}$ & $\begin{array}{l}\text { Primary } \\
\text { infertility (\%) }\end{array}$ & $\begin{array}{l}\text { Secondary } \\
\text { infertility (\%) }\end{array}$ & Total \\
\hline$<25$ & $29(78.4)$ & $08(21.6)$ & $37(41.1)$ \\
$26-30$ & $23(67.6)$ & $11(32.4)$ & $34(37.8)$ \\
$31-35$ & $10(66.7)$ & $05(33.3)$ & $15(16.7)$ \\
$>35$ & $04(4.4)$ & 0 & $04(4.4)$ \\
Total & $66(73.3)$ & $24(26.7)$ & $90(100)$ \\
\hline
\end{tabular}

Table 2: Distribution according to hysteroscopy findings in the study subjects

\begin{tabular}{llc}
\hline Hysteroscopy & Number & Percentage \\
\hline Normal & 68 & 82.2 \\
Endometrial polyps & 10 & 11.1 \\
Endometrium hyperplastic & 03 & 03.3 \\
Atropic endometrium & 01 & 01.1 \\
Hypoplastic uterus & 01 & 01.1 \\
Partial septum present & 05 & 05.6 \\
Submucous fibroid & 01 & 01.1 \\
Intrauterine adhesions & 01 & 01.1 \\
Total & 90 & 100.0 \\
\hline
\end{tabular}

Table 3: Distribution according to laparoscopic findings in uterus among the study subjects

\begin{tabular}{llc}
\hline $\begin{array}{l}\text { Laparoscopic findings } \\
\text { in uterus }\end{array}$ & Number & Percentage \\
\hline Normal & 74 & 82.2 \\
Hypoplastic & 01 & 1.1 \\
Fibroids & 12 & 13.3 \\
Unicornuate & 02 & 2.2 \\
Bicornuate & 01 & 1.1 \\
Total & 90 & 100.00 \\
\hline
\end{tabular}

Table 4: Distribution according to laparoscopic pelvic pathology findings among the study subjects

\begin{tabular}{llc}
\hline Laparoscopic findings in pelvis & Number & Percentage \\
\hline Endometriosis (minimal) & 10 & 32.3 \\
Endometriosis (mild) & 06 & 19.4 \\
Moderate endometriosis & 09 & 29.0 \\
Severe endometriosis & 02 & 06.5 \\
Omental adhesions & 04 & 12.9 \\
Total & 31 & 100.0 \\
\hline
\end{tabular}

out of 90 subjects, 66 (73.3\%) were primary infertility and 24 (26.7\%) were secondary infertility which is comparable to study by AM Elbareg et al. ${ }^{3}$

The commonest hysteroscopic uterine cavity abnormality was endometrial polyp seen in $10 \%$. The same is observed in studies done by Zhang et al., Nayak et al., and Elbareg et al. ${ }^{3-5}$

The second most common hysteroscopic uterine cavity abnormality in our study was septate uterus which was similar to study by Nayak et al., ${ }^{5}$ where septate uterus was found at higher incidence of $10 \%$ in their study (Tables 7 to 9).
Table 5: Distribution according to laparoscopic finding of fallopian tubes in the study subjects

\begin{tabular}{|c|c|c|c|c|}
\hline \multirow[b]{2}{*}{ Findings } & \multicolumn{2}{|c|}{ Right tube } & \multicolumn{2}{|c|}{ Left tube } \\
\hline & Number & Percentage & Number & Percentage \\
\hline Normal & 74 & 60.0 & 70 & 54.5 \\
\hline $\begin{array}{l}\text { Peritubal adhe- } \\
\text { sions }\end{array}$ & 04 & 10.0 & 06 & 13.6 \\
\hline $\begin{array}{l}\text { Tubo-ovarian } \\
\text { mass }\end{array}$ & - & - & 01 & 02.3 \\
\hline Hydrosalphinx & 02 & 05.0 & 02 & 04.5 \\
\hline Hematosalpinx & 01 & 02.5 & - & - \\
\hline Kinking & 01 & 02.5 & - & - \\
\hline Tortuous & 02 & 05.0 & 02 & 04.5 \\
\hline Stretched tubes & 02 & 05.0 & 04 & 09.1 \\
\hline Fimbrial cyst & 02 & 05.0 & - & - \\
\hline $\begin{array}{l}\text { Not visualized } \\
\text { due to adhesions }\end{array}$ & 01 & 02.5 & 03 & 06.8 \\
\hline Absent tubes & 01 & 02.5 & 02 & 04.5 \\
\hline Total & 90 & 100.0 & 90 & 100.0 \\
\hline
\end{tabular}

Table 6: Distribution according to laparocscopic findings of ovaries in the study subjects

\begin{tabular}{llllll}
\hline & \multicolumn{3}{c}{ Right ovary } & & \multicolumn{2}{c}{ Left ovary } \\
\cline { 2 - 3 } \cline { 6 - 6 } Findings & Number & Percentage & & Number & Percentage \\
\hline Normal & 41 & 45.6 & & 45 & 50.0 \\
Polycystic ovaries & 27 & 30.0 & & 27 & 30.0 \\
Endometriotic & 09 & 10.0 & & 02 & 02.2 \\
cyst & 09 & & & \\
Ovarian cyst & 07 & 07.8 & & 07 & 07.8 \\
Adhesions & 02 & 02.2 & & 07 & 07.8 \\
Paraovarian cyst & 01 & 01.1 & & 01 & 01.1 \\
Could not be & 03 & 03.3 & & 01 & 01.1 \\
visualized & & & & & \\
Total & 90 & 100.0 & & 90 & 100.0 \\
\hline
\end{tabular}

In a study by Elbareg et al., ${ }^{3}$ significant hysteroscopy findings were noted in $50 \%$ of cases, and in our study significant findings were noted in $24.4 \%$.

It has been associated with increased miscarriage rates, but there is no evidence of lower pregnancy rates. ${ }^{3}$

In our study, polypectomy was done in $5.55 \%$ cases which are comparable to study by Keya Vaid et al. ${ }^{6}$

In our study, tubal cannulation was performed hysteroscopically in 2 (2.2\%) cases out of 90 cases, compared to Keya et al., where hysteroscopic cannulation was performed in $8 \%$.

Laparoscopy with concurrent chromopertubation is considered as gold standard for diagnosing tubal functions. Hei et al. found that $6.04 \%$ had bilateral tubal occlusion, and $5.69 \%$ had unilateral tubal occlusion. ${ }^{7}$

In our study, $8.9 \%$ had bilateral tubal occlusion, $16.7 \%$ had unilateral tubal occlusion, and bilateral tubal patency was demonstrated in $74.4 \%$. In a study by Godinjak Z, bilateral tubal patency was demonstrated in $86.67 \%$, bilateral tubal block in $5 \%$, and unilateral block in $8.33 \%$ of patients. ${ }^{8}$

In our study, laparoscopic findings of uterus were as follows: $74(78.9 \%)$ of them had normal study, $12(13.3 \%)$ of them had 
Table 7: Distribution according to chromopertubation findings in the study subjects

\begin{tabular}{llc}
\hline Findings & Number & Percentage \\
\hline Normal & 67 & 74.4 \\
Unilateral block & 15 & 16.7 \\
Bilateral block & 08 & 08.9 \\
Total & 90 & 100.0 \\
\hline
\end{tabular}

Table 8: Distribution according to laparoscopic interventions in the study subjects

\begin{tabular}{llc}
\hline Laparoscopic interventions & Number & Percentage \\
\hline Diagnostic & 27 & 30 \\
Ovarian cystectomy & 17 & 18.8 \\
Paraovarian cystectomy & 03 & 3.3 \\
Ovarian drilling & 26 & 28.8 \\
Adhesiolysis & 02 & 2.22 \\
Myomectomy & 07 & 7.77 \\
Fimbrial cystectomy & 02 & 2.22 \\
Fulguration of endometriotic & 04 & 4.44 \\
spots & & \\
Unilateral salpingectomy & 02 & 2.22 \\
Total & 90 & 100 \\
\hline
\end{tabular}

Table 9: Distribution according to hysteroscopic interventions in the study subjects

\begin{tabular}{llc}
\hline $\begin{array}{l}\text { Hysteroscopic } \\
\text { interventions }\end{array}$ & Number & Percentage \\
\hline Diagnostic & 66 & 66.6 \\
Curettage & 08 & 8.8 \\
Hysteroscopic & 02 & 2.2 \\
cannulation & & \\
Polpectomy & 05 & 5.5 \\
Septal resection & 05 & 5.5 \\
Submucosal fibroid & 01 & 1.1 \\
resection & & \\
Tubal block released & 02 & 2.2 \\
Adhesiolysis & 01 & 1.1 \\
Total & 90 & 100.0 \\
\hline
\end{tabular}

fibroid uterus, 5 (20.8\%) had septate uterus, 1 (1.1\%) each had unicornuate uterus and hypoplastic uterus. Mullerian anomalies were comparatively more in our study when compared to Suman et al. which had $4 \%$ congenital anomalies.

Our study revealed myomas in $13.3 \%$ patients on laparoscopy and $1.1 \%$ on hysteroscopy which is comparable to study by Zhan et al. ${ }^{4}$ which revealed myomas in $15 \%$. Also in a review by Pritts et al., ${ }^{9}$ they found that fibroids causing intracavitary distortion result in decreased pregnancy rates. ${ }^{4,9}$

In our study, $60 \%$ of the cases had normal fallopian tubes, and most common pathological finding was hydrosalphinx seen in $5 \%$, compared to Keya vaid et al. ${ }^{6}$ Hydrosalphinx was observed in $2.59 \%$; however, most common pathology in their study were fimbrial cyst $9.84 \%$. Other pathology in tubes found in our study were as follows: 6 (13.6\%) had peritubal adhesions, 2 (5\%) had tortuous, stretched, and kinking tubes and 1 each (2.5\%) had tuboovarian mass, hematosalphinx, absent tubes, and tube could not be visualized in 1 case (2.5\%). ${ }^{6}$

In the study done by Shobha Dhananjay et al., ${ }^{10}$ PCOS was the commonest finding noted in $18.99 \%$ similar to our study. The other more commonly seen pathology in ovary in our study was endometriomas with incidence of $12.6 \%$.

The surgical removal of endometriotic implants in minimalmild severity endometriosis was shown to improve fertility in two randomized controlled studies. Thus, all patients with endometriosis should have all visible implants excised during laparoscopic diagnosis. According to Adamson, in the more severe stages of endometriosis, a surgical approach that normalizes pelvic anatomic distortion and provides adhesiolysis can enhance fertility ${ }^{11,12}$

In our study, endometriosis was seen in total of 27 cases which were subclassified according to ASRM criteria, and fulguration of endometriotic spots was performed in 4 (4.4\%). ${ }^{6}$ Endometrioma resection was done in $12.2 \%$.

\section{Conclusion}

Based on results of this study it be concluded that hysterolaparoscopy is an effective and safe tool in comprehensive evaluation of infertility to diagnose and treat the various pathological conditions in the same time. Hence, it is an essential tool for the diagnosis, treatment, and prognosis, as it allows the gynecologist to develop the plan of management for infertile women.

\section{References}

1. Ombelet W, Cooke I, Dyer S, et al. Infertility and the provision of infertility medical services in developing countries. Hum Reprod Update 2008;14(6):605-621. DOI: 10.1093/humupd/dmn042.

2. Dyer SJ. International estimates on infertility prevalence and treatment seeking: potential need and demand for medical care. Hum Reprod 2009;24(9):2379-2380. DOI: 10.1093/humrep/dep219.

3. Elbareg AM, Essadi FM, Elmehashi MO, et al. Hysteroscopy in libyan women with recurrent pregnancy loss. Sudan J Med Sci 2014;9: 239-244.

4. Zhang E, Zhang $Y$, Fang L, et al. Combined Hysterolaparoscopy for the diagnosis of femaleinfertility: a retrospective study of 132 patients in China. Mater Sociomed 2014;26(3):156-157. DOI: 10.5455/ msm.2014.26.156-157.

5. Nayak PK, Mahapatra PC, Mallick J, et al. Role of diagnostic hysterolaparoscopy in the evaluation of infertility: a retrospective study of 300 patients. J Hum Reprod Sci 2013;6(1):32-34. DOI: 10.4103/09741208.112378

6. Vaid K, Mehra S, Verma M, et al. Pan endoscopic approach 'Hysterolaparoscopy' as an initial procedure in selected infertile women. J Clin Diagn Res 2014;8(2):95-98.

7. Heis $\mathrm{M}$, Amarin $\mathrm{Z}$, et al. Uterine and tubal anatomical abnormalities in infertile women: diagnosis with routine hysterosalpingography prior to selective laparoscopy. SA J Radiol 2011(4):121-122. DOI: 10.4102/ sajr.v15i4.354.

8. Godinjak Z, Idrizbegovic E. Should diagnostic hysteroscopy be a routine procedure during diagnostic laparoscopy in infertile women? Bosnian J Basic Med 2008;8(1):44-47. DOI: 10.17305/bjbms.2008.2996.

9. Pritts EA, Parker WH, Olive DL. Fibroids and infertility: an updated systematic review of the evidence. Fertil Steril 2009;91(4):1215-1223. DOI: 10.1016/j.fertnstert.2008.01.051.

10. Shobha D, Madhu KN, Amiti A. Role of diagnostic hysterolaparoscopy in evaluation of primary and secondary infertility. J Evolut Med Dent Sci 2014;1(3):2194-2207. DOI: 10.14260/jemds/2014/2126. 
11. Marcoux S, Maheux R, Bérubé S. Laparoscopic surgery in infertile women with minimal or mild endometriosis. Canadian collaborative group on endometriosis. N Engl J Med 1997;337(4):217-220. DOI: 10.1056/NEJM199707243370401.
12. Parazzini F. Ablation of lesions or no treatment in minimal-mild endometriosis in infertile women: a randomized trial. Gruppo Italian per lo studio dell'Endometriosi. Hum Reprod 1999;14(5):1332-1334. DOI: 10.1093/humrep/14.5.1332. 